\title{
THE ORAL GOLD COMPOUND AURANOFIN TRIGGERS ARACHIDONATE RELEASE AND CYCLOOXYGENASE METABOLISM IN THE ALVEOLAR MACROPHAGE
}

\author{
Marc Peters-Golden and Candace Shelly \\ Division of Pulmonary and Critical Care Medicine \\ Department of Internal Medicine \\ University of Michigan and Veterans Administration Medical Centers \\ Ann Arbor, MI 48109
}

\begin{abstract}
We examined the effect of in vitro incubation with the oral gold compound auranofin (AF) on arachidonic acid (AA) release and metabolism by rat alveolar macrophages (AMs). AF stimulated dose- and time-dependent release of ${ }^{14} \mathrm{C}$-AA from prelabeled AMs, which reached $4.7 \pm 0.3 \%$ (mean \pm SEM) of incorporated radioactivity at $10 \mu \mathrm{g} / \mathrm{ml}$ for $90 \mathrm{~min}$, as compared to $0.5 \pm 0.1 \%$ release following control incubation for $90 \mathrm{~min}(\mathrm{p}<0.001)$. Similar dose- and time-dependent synthesis of thromboxane ( $T x$ ) $A_{2}$ (measured as $\mathrm{TxB}_{2}$ ) and prostaglandin (PG) $\mathrm{E}_{2}$ was demonstrated by radioimmunoassay of medium from unlabeled cultures, reaching 18 -fold and 9-fold, respectively, of the control values at $10 \mu \mathrm{g} / \mathrm{ml} \mathrm{AF}$ for $90 \mathrm{~min}$ ( $\mathrm{p}<0.001 \mathrm{for}$ both). AF-induced $\mathrm{TxB}_{2}$ and $\mathrm{PGE}_{2}$ synthesis was inhibited by indomethacin as well as by pretreatment with methylprednisolone. No increase in the synthesis of immunoreactive leukotrienes (LT) $\mathrm{B}_{4}$ or $\mathrm{C}_{4}$ was noted at any dose or time of $\mathrm{AF}$. High performance liquid chromatographic separation of ${ }^{14} \mathrm{C}$-eicosanoids synthesized by prelabeled AMs confirmed that $\mathrm{AF}$ induced the release of free AA and its metabolism to cyclooxygenase, but not 5-lipoxygenase, metabolites. The ability of AF to trigger macrophage AA metabolism may be relevant to the exacerbation of certain inflammatory processes which sometimes accompany gold therapy.
\end{abstract}

\section{INTRODUCTION}

Gold salts are efficacious in the treatment of rheumatoid arthritis (1) and, perhaps, asthma $(2,3)$. However, they have been observed to exacerbate adjuvant arthritis in the rat (4), and are well-recognized to cause pneumonitis in humans (5). Because macrophage-derived metabolites of arachidonic acid (AA) are thought to be important in the pathogenesis of chronic inflammatory disorders (6) such as rheumatoid arthritis and asthma, and because the macrophage is a putative target cell for the anti-inflammatory effects of chrysotherapy (7), we have initiated studies to examine the effects of in vitro incubation with the oral gold compound auranofin (AF) on macrophage AA metabolism. In a previous study (8), we observed that therapeutic concentrations of AF inhibited ionophore A23187-induced 5-lipoxygenase metabolism in the rat alveolar macrophage $(\Lambda \mathrm{M})$. However, thromboxane $\mathrm{A}_{2}$ synthesis was concomitantly augmented by AF. Therefore, in the present study we have examined the effect of AF alone on AA metabolism in the same cell. Our results indeed indicate that AF triggers dose- and timedependent release of AA and its cyclooxygenase metabolites. These findings may be relevant to the seemingly paradoxical potential of gold compounds to exacerbate inflammation. 


\section{METHODS}

Macrophage isolation and culture. Alveolar macrophages were obtained by bronchoalveolar lavage from respiratory disease-free $125-150 \mathrm{~g}$ female Wistar rats (Charles River, Portage, MI), as previously described (9). Two $\times 10^{6}$ cells suspended in medium 199 with modified Earle's salts (M199; GIBCO, Grand Island, NY) were plated in $35 \times 10 \mathrm{~mm}$ plastic culture dishes (Falcon Plastics, Oxnard, CA) and cultured at $37{ }^{\circ} \mathrm{C}$ in a humidified atmosphere of $5 \% \mathrm{CO}_{2}$ in air. After $1 \mathrm{~h}$, non-adherent cells were removed by washing twice with Hanks' balanced salt solution (HBSS; GIBCO). The resultant adherent cell population has been found to contain $95 \%$ AMs by morphologic criteria and esterase staining (9) with viability as assessed by trypan blue exclusion exceeding $90 \%$. Macrophage monolayers were then cultured overnight (16 h) in M199 containing $10 \%$ heat-inactivated newborn calf serum (NCS; GIBCO) in the presence or absence of radiolabeled AA prior to experimental incubations. In some experiments, overnight incubations were carried out in the presence of $1 \mu \mathrm{M}$ methylprednisolone (10). Following overnight culture, these monolayers have been found to contain approximately $8.5 \mu \mathrm{g}$ DNA (9) and $100 \mu \mathrm{g}$ protein (11).

Prelabeling of macrophage cultures. In selected experiments, cellular lipids were prelabeled by including $0.2 \mu \mathrm{Ci}$ of $\left[1-{ }^{14} \mathrm{C}\right] \mathrm{AA}$ (specific activity $54-57 \mathrm{mCi} / \mathrm{mmol}$, DupontNew England Nuclear, Boston, MA) in the medium during overnight culture (11). The uptake of radiolabel by macrophage cultures, determined as described previously (9), was $31.6 \pm 1.4 \%$ (mean $\pm S E M, n=4$ ).

Incubations. Duplicate cultures of unlabeled or prelabeled AMs were washed twice with HBSS and incubated for 30,60, or 90 min with $1 \mathrm{ml}$ of M199 containing $0,2,5$, or 10 $\mu \mathrm{g} / \mathrm{ml}$ AF. Auranofin (generously provided by Smith Kline \& French Laboratories, Philadelphia, PA) was prepared as a stock solution at $20 \mathrm{mg} / \mathrm{ml}$ in DMSO, and diluted directly into M199 to reach the desired final concentrations. All cultures contained DMSO at a final concentration of $0.5 \%$. In some experiments, indomethacin (Sigma), 5 $\mu \mathrm{M}$ in $0.05 \%$ ethanol (final concentration) was added to cultures simultaneous with AF. Neither viability nor eicosanoid synthesis was affected by DMSO or ethanol in the concentrations utilized. In selected experiments, prelabeled cultures were incubated for 30 min with the agonist ionophore A23187 (Calbiochem-Behring Corp., La Jolla, CA), $1 \mu \mathrm{M}$ in $0.5 \%$ DMSO, or the detergent Triton-X 100 (Sigma), 0.01-0.1\%.

Release of total radioactivity and free ${ }^{14} \mathrm{C}$-AA. Total radioactivity released from prelabeled cells was determined by counting duplicate $50 \mu \mathrm{l}$ aliquots of medium in $9 \mathrm{ml}$ of ACS scintillant (Amersham Corp., Arlington Heights, IL). To assess deacylation of free ${ }^{14} \mathrm{C}$-AA from prelabeled cells, lipids were extracted from cells plus medium with chloroform/methanol $(2: 1, \mathrm{vv})$, and separated by thin layer chromatography (TLC) on Silica Gel 60 plates developed with hexane/diethyl ether/acetic acid (70:30:1, v/v/v), as described (12). Spots migrating with authentic AA standard (Nu-chek Prep, Inc., Elysian, MN) were visualized by exposure to iodine vapor, cut out, eluted with methanol, and radioactivity quantitated by liquid scintillation spectrometry. Both total counts and free ${ }^{14} \mathrm{C}$-AA counts were expressed as a percentage of total incorporated radioactivity.

Extraction of eicosanoids. Eicosanoids were extracted from culture media of prelabeled or unlabeled cells using $\mathrm{C}_{18}$ Sep-Pak cartridges (Waters Associates, Milford, MA), and 
a modification (11) of the method of Westcott, et. al. (13). Recoveries for this extraction procedure, assessed using tritiated standards (Dupont-New England Nuclear) added to $\mathrm{M} 199$, were $65-70 \%$ for thromboxane $\mathrm{B}_{2}\left(\mathrm{TxB}_{2}\right.$, the stable metabolite of $\left.\mathrm{TxA}_{2}\right)$, leukotriene $\mathrm{C}_{4}\left(\mathrm{LTC}_{4}\right)$, and leukotriene $\mathrm{B}_{4}\left(\mathrm{LTB}_{4}\right)(11)$.

Reverse-phase high performance liquid chromatography (RP-HPLC). Radiolabeled eicosanoids were separated by RP-HPLC with a Waters HPLC system and a Waters 5 $\mu \mathrm{m}$ Bondapak $\mathrm{C}_{18}$ column, as previously described (10). The mobile phase, acetonitrile/water/trifluoroacetic acid, was used at a $1 \mathrm{ml} / \mathrm{min}$ flow rate. Cyclooxygenase metabolites were eluted during an initial isocratic phase $(33: 67: 0.1, \mathrm{v} / \mathrm{v} / \mathrm{v})$ and lipoxygenase metabolites and free AA during a stepwise gradient increase of acetonitrile to $100: 0: 0.1(\mathrm{v} / \mathrm{v} / \mathrm{v})$. The eluate was continuously monitored for UV absorbance $(210$ $\mathrm{nm}$ for cyclooxygenase products and free AA, $280 \mathrm{~nm}$ for leukotrienes, and $235 \mathrm{~nm}$ for monohydroxyeicosatetraenoic acids). Eicosanoids were identified by their co-elution with authentic standards. One ml eluate fractions were collected and products quantitated by liquid scintillation spectrometry in $6 \mathrm{ml}$ scintillant. Authentic cyclooxygenase metabolites were the generous gift of Dr. J. Pike (Upjohn Co., Kalamazoo, MI) and lipoxygenase metabolites, of Dr. J. Rokach (Merck Frosst, Inc., Quebec, Canada).

Radioimmunoassays. Thromboxane $\mathrm{B}_{2}$, prostaglandin $\mathrm{E}_{2}\left(\mathrm{PGE}_{2}\right), \mathrm{LTB}_{4}$, and $\mathrm{LTC}_{4}$ were quantitated by radioimmunoassays (RIA). Sep-Pak extracts were dried, dissolved in $1 \mathrm{ml}$ of phosphate-buffered saline containing $0.1 \%$ gelatin, and $0.1 \mathrm{ml}$ aliquots assayed in duplicate. The sources, sensitivities, and cross-reactivities of the antibodies employed have been described previously (14). In all cases, concentrations of immunoreactive eicosanoids were corrected for recovery.

Assessment of viability by exclusion of trypan blue. Following control or experimental incubation, medium was removed and replaced with $0.05 \%$ trypan blue (Sigma) in normal saline. After $10 \mathrm{sec}$, dye was removed by aspiration and cultures immediately examined under light microscopy. The percentage of cells excluding trypan blue was determined as the average value from 200 cells counted in each of the duplicate cultures.

Data analysis. All data are expressed as mean values \pm SEM. Viability, total radioactivity release, free ${ }^{14} \mathrm{C}$-AA release, and immunoreactive eicosanoids were determined in duplicate culture plates for each condition and the average calculated to yield a single data point. Unless otherwise indicated, all data represent the results from 3 individual experiments. The significance of differences between group means was assessed by one-way analysis of variance and the Newman-Keuls Multiple Range Test. In all cases, a $\mathrm{p}$ value $<0.05$ was considered significant.

\section{RESULTS}

Effect of AF on release of total radioactivity and ${ }^{14} \mathrm{C}$-AA. In unstimulated cultures, approximately $1.5 \%$ of incorporated radioactivity was released into culture medium as free AA plus eicosanoids at all time points (Fig. 1A). No increases in release of radioactivity were observed with $\mathrm{AF}$ at $2 \mu \mathrm{g} / \mathrm{ml}$. Five $\mu \mathrm{g} / \mathrm{ml} \mathrm{AF}$ induced time-dependent release of radioactivity, which approached statistical significance as compared to control at $60 \mathrm{~min}$ $(0.05<p<0.1)$ and was highly significant $(p<0.001)$ at $90 \mathrm{~min}$. The highest dose of AF $(10 \mu \mathrm{g} / \mathrm{ml})$ also stimulated time-dependent release of radioactivity, which reached 10.3 $\pm 1.5 \%$ at $90 \mathrm{~min}$. 

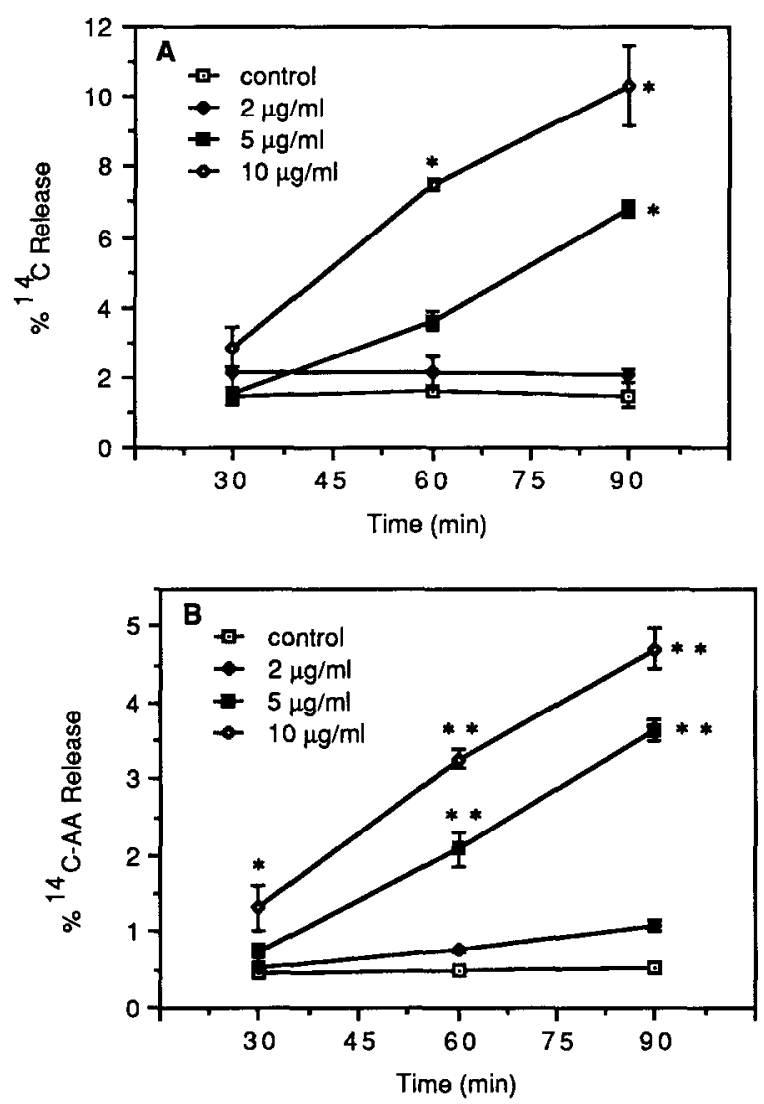

Fig. 1. Effect of AF on release of total radioactivity and radiolabeled AA from prelabeled cells. ${ }^{14} \mathrm{C}$-AA prelabeled AMs were incubated for the indicated times in the presence or absence of $\mathrm{AF}$ at the concentrations shown. Release of total ${ }^{14} \mathrm{C}$ radioactivity (A) and of free ${ }^{14} \mathrm{C}$-AA (B) were determined and are plotted as the percent of total incorporated radioactivity measured prior to the experimental incubations. Each point represents the mean \pm SEM of 3 independent experiments, each performed in duplicate.

Since fatty acid deacylation is the initial and probably the rate-limiting step in the metabolism of AA (15), we quantitated free ${ }^{14} \mathrm{C}$-AA in cells plus medium of cultures incubated for various times with and without $\mathrm{AF}$ in various concentrations (Fig. 1B). Approximately $0.5 \%$ of the initial incorporated radioactivity was constitutively released as free AA at all time points. At $2 \mu \mathrm{g} / \mathrm{ml} \mathrm{AF}$, AA release tended to increase over time, reaching approximately $1 \%$ at $90 \mathrm{~min}(0.05<\mathrm{p}<0.1)$. Significant increases in AA re- 
lease occurred with $5 \mu \mathrm{g} / \mathrm{ml}$ at $60 \mathrm{~min}$ and $90 \mathrm{~min}$ ( $\mathrm{p}<0.001$ vs control at both time points), and with $10 \mu \mathrm{g} / \mathrm{ml} \mathrm{AF}$ at all time points, reaching $4.7 \pm 0.3 \%$ at $90 \mathrm{~min}$.
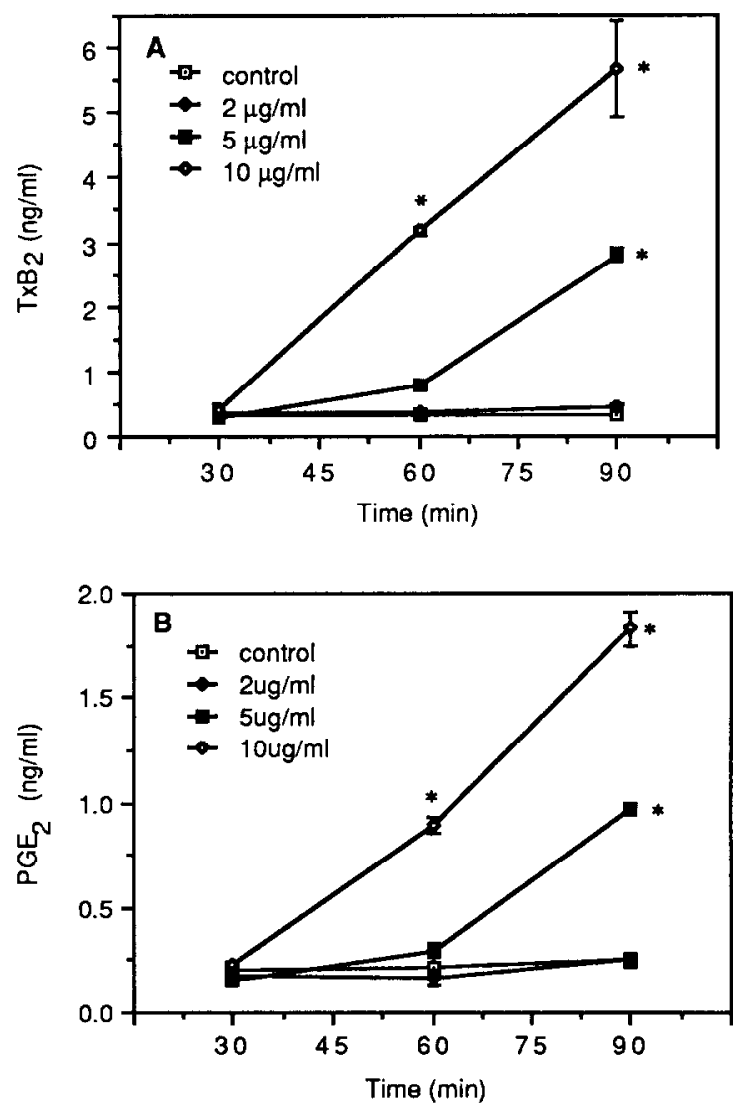

Fig. 2. Effect of $A F$ on macrophage synthesis of immunoreactive $\mathrm{TxB}_{2}$ (A) and $\mathrm{PGE}_{2}(\mathrm{~B})$. Unlabeled AMs were incubated for the indicated times in the presence or absence of $\mathrm{AF}$ at the concentrations shown and eicosanoids quantitated by RIA. Data are expressed in $\mathrm{ng} / \mathrm{ml}$ ( $\mathrm{ng} / \mathrm{plate}$ ) and represent the mean \pm SEM of 3 independent experiments, each performed in duplicate.

Effect of AF on macrophage eicosanoid synthesis. Radioimmunoassay of media from unlabeled cultures similarly demonstrated dose- and time-dependent synthesis of $\mathrm{TxB}_{2}$ (Fig. 2A) and $\mathrm{PGE}_{2}$ (Fig. 2B). As compared to control cultures incubated for comparable times, these differences were highly significant $(\mathrm{p}<0.001)$ for $5 \mu \mathrm{g} / \mathrm{ml} \mathrm{AF}$ at 90 min and $10 \mu \mathrm{g} / \mathrm{ml} \mathrm{AF}$ at both 60 and $90 \mathrm{~min}$. At $10 \mu \mathrm{g} / \mathrm{ml} \mathrm{AF}$ incubation for $90 \mathrm{~min}$, 
the maximal levels of immunoreactive $\mathrm{TxB}_{2}$ and $\mathrm{PGE}_{2}$ were $5.66 \pm 0.93 \mathrm{ng} / \mathrm{ml}$ and $1.83 \pm 0.10 \mathrm{ng} / \mathrm{ml}$, respectively. Of note, the $\mathrm{TxB}_{2}: \mathrm{PGE}_{2}$ ratio also increased with $\mathrm{AF}$ stimulation from a value of approximately 1.5 in unstimulated cultures to a value of $>3$ in AMs incubated with $10 \mu \mathrm{g} / \mathrm{ml} \mathrm{AF}$ for $90 \mathrm{~min}$. This reflected a 9 -fold increase in $\mathrm{PGF}_{2}$ synthesis and a 18 -fold increase in $\mathrm{TxB}_{2}$ synthesis under maximal conditions as compared to control conditions.

In contrast to the marked stimulatory effects of $\mathrm{AF}$ on $\mathrm{AM}$ synthesis of $\mathrm{TxB}_{2}$ and $\mathrm{PGE}_{2}$, no such stimulation of immunoreactive $\mathrm{LTB}_{4}$ or $\mathrm{LTC}_{4}$ synthesis was observed at any time or dose of AF. Table 1 depicts the results of experiments utilizing 90 min incubations, but no increase in LT synthesis was seen at shorter time points either.

The effects of AF on arachidonate release and metabolism were also investigated by RP-HPLC analysis of radiolabeled eicosanoids released by prelabeled cells. Fig. 3 shows RP-HPLC radioactivity elution profiles from a representative experiment in which AMs were incubated for 60 min with medium alone (A) or AF, $5 \mu \mathrm{g} / \mathrm{ml}$ (B). Each chromatogram represents the elution profile of eicosanoids pooled from duplicate culture plates. As shown, unstimulated cultures released a single peak of radioactivity corresponding to a small amount of free AA. In contrast, cultures stimulated with AF demonstrated an increased release of free AA, as well as peaks corresponding to the cyclooxygenase products $\mathrm{TxB}_{2}, \mathrm{PGE}_{2}$, and HHT. Although small peaks corresponding to 15-hydroxyeicosateraenoic acid (15-HETE) and 12-HETE were present, no peaks corresponding to the 5-lipoxygenase products $\mathrm{LTC}_{4}$, $\mathrm{LTB}_{4}$, or 5-HETE were detected.

Table 1. Effects of AF on Macrophage

$\mathrm{LTB}_{4}$ and $\mathrm{LTC}_{4}$ synthesis ${ }^{\mathrm{a}}$

\begin{tabular}{|c|c|c|}
\hline AF concentration $b$ & $\mathrm{LTB}_{4}{ }^{\mathrm{c}}$ & $\mathrm{LTC}_{4}{ }^{c}$ \\
\hline control & $0.22 \pm 0.04$ & $0.24 \pm 0.12$ \\
\hline $2 \mu \mathrm{g} / \mathrm{ml}$ & $0.17 \pm 0.09$ & $0.17 \pm 0.01$ \\
\hline $5 \mu \mathrm{g} / \mathrm{ml}$ & $0.17 \pm 0.06$ & $0.13 \pm 0.06$ \\
\hline $10 \mu \mathrm{g} / \mathrm{ml}$ & $0.18 \pm 0.08$ & $0.10 \pm 0.01$ \\
\hline
\end{tabular}

\footnotetext{
aResults are the mean \pm SEM from 3 independent experiments, each performed in duplicate.

bAll incubations shown were for $90 \mathrm{~min}$.

cImmunoreactive LT values expressed in $\mathrm{ng} / \mathrm{ml}$.
}

Effects of indomethacin and methylprednisolone on AF-induced eicosanoid synthesis. The effects of indomethacin $(5 \mu \mathrm{M})$ on immunoreactive eicosanoid synthesis induced by $5 \mu \mathrm{g} / \mathrm{ml} \mathrm{AF}$ for $60 \mathrm{~min}$ were examined. Indomethacin completely inhibited AF-induced synthesis of $\mathrm{TxB}_{2}$ (AF, $0.84 \pm 0.15 \mathrm{ng} / \mathrm{ml}$; AF plus indomethacin, $0.11 \pm 0.01 \mathrm{ng} / \mathrm{ml}$ ) and $\mathrm{PGE}_{2}$ (AF, $0.33 \pm 0.03$; AF plus indomethacin, $0.15 \pm 0.01$ ) (mean \pm one-half the range, $n=2)$. At the same time, indomethacin failed to augment synthesis of $\mathrm{LTB}_{4}(\mathrm{AF}$, $0.17 \pm 0.02 \mathrm{ng} / \mathrm{ml}$; AF plus indomethacin, $0.16 \pm 0.04$ ) (mean \pm one-half the range, $\mathrm{n}=2$ ) in cultures incubated with $\mathrm{AF}$.

In one experiment, the effect of $16 \mathrm{~h}$ pretreatment with the glucocorticoid methylprednisolone $(1 \mu \mathrm{M})$ on $A F$-induced $\mathrm{TxB}_{2}$ synthesis was evaluated. When im- 
munoreactive $\mathrm{TxB}_{2}$ levels were corrected for control amounts, methylprednisolone pretreatment resulted in a $53 \%$ inhibition of $\mathrm{TxB}_{2}$ synthesis induced by $5 \mu \mathrm{g} / \mathrm{ml}$ AF for 60 min (data not shown).

Effect of $\mathrm{AF}$ on macrophage viability. Macrophage viability was preserved in both control cultures and cultures exposed to $2 \mu \mathrm{g} / \mathrm{ml} \mathrm{AF}$ for up to 90 min (Fig. 4). At 5 $\mu \mathrm{g} / \mathrm{ml} \mathrm{AF}$, viability was reduced only at the $90 \mathrm{~min}$ incubation time ( $\mathrm{p}<0.001 \mathrm{vs} 90 \mathrm{~min}$ control). At $10 \mu \mathrm{g} / \mathrm{ml} \mathrm{AF}$, time-related cytotoxicity was observed at incubation times of
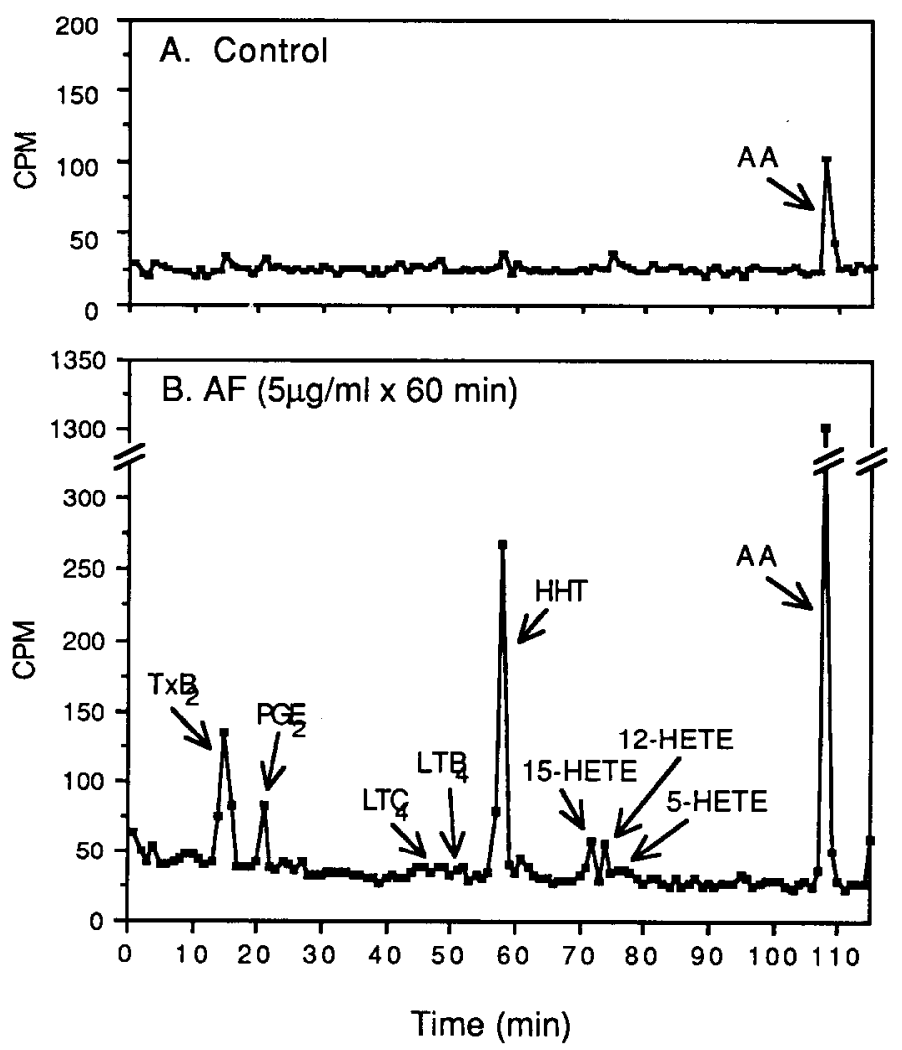

Fig. 3 RP-HPLC analysis of radiolabeled eicosanoids induced by AF. Prelabeled cells were incubated for $60 \mathrm{~min}$ in the absence (A) or presence (B) of $5 \mu \mathrm{g} / \mathrm{ml} \mathrm{AF}$, after which eicosanoids were extracted and separated by RPHPLC. Data represent results from pooled duplicate cultures. The retention times of authentic standards are indicated by arrows.

both $60 \mathrm{~min}(\mathrm{p}<0.005$ vs $60 \mathrm{~min}$ control) and $90 \mathrm{~min}$ ( $p<0.001$ vs $90 \mathrm{~min}$ control), at which time only $33 \%$ of cells excluded trypan blue. 
Relationship between AA release and metabolism and cytotoxicity induced by AF. It was apparent from the foregoing results that $\mathrm{AF}$ had the capacity to both trigger $\mathrm{AA}$ release and cyclooxygenase metabolism, as well as to cause cytotoxicity, in AM cultures. In order to investigate the relationship between cell injury and AA release and metabolism in the AM, we related cell viability (as assessed by trypan blue exclusion), total release of radioactivity, and the release of free arachidonate and metabolites (by RP-HPLC analysis) in prelabeled cultures incubated under a variety of conditions. For this purpose, we examined AMs exposed to: 1$)$ AF under both non-toxic $(5 \mu \mathrm{g} / \mathrm{ml}$ for $60 \mathrm{~min}$ ) and toxic (50 $\mu \mathrm{g} / \mathrm{ml}$ for $90 \mathrm{~min}$ ) conditions; 2) calcium ionophore A23187, a maximal stimulus for macrophage AA metabolism; and 3) the detergent Triton-X 100 at various concentrations. For each condition, the total amount of radiolabeled AA plus metabolites released into culture medium and eluted by RP-HPLC was expressed relative to the amount of ${ }^{14} \mathrm{C}$-AA incorporated into cells, as well as to the amount of total radioactivity released into medium.

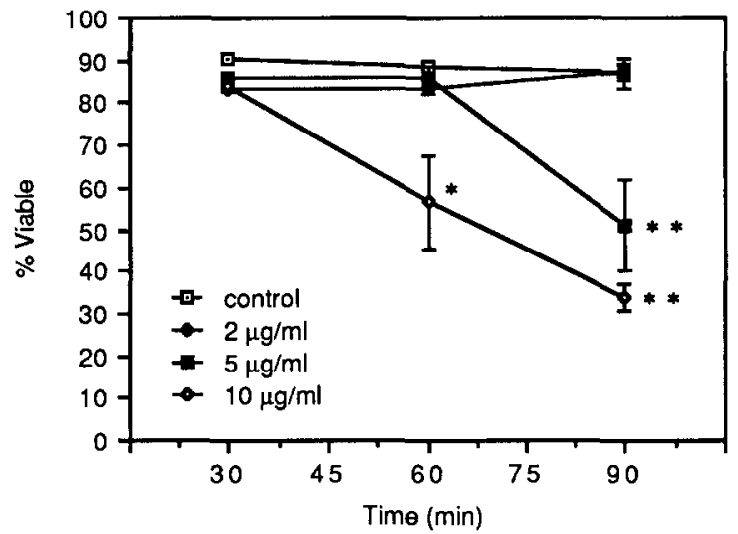

Fig 4. Effect of AF on macrophage viability. AM cultures were incubated for the indicated times with either medium alone or medium containing AF at the concentration shown. The percent of 200 cells counted which excluded trypan blue is plotted. Each point represents the mean \pm SEM of 3 independent experiments, each performed in duplicate.

As demonstrated in Table $2,5 \mu \mathrm{g} / \mathrm{ml} \mathrm{AF}$ and A23187 were respectively weak and potent agonists of AA metabolism in the absence of cytotoxicity. In contrast, an inverse relationship between viability and total release of radioactivity was observed in cultures exposed to high-dose AF, $0.01 \%$ Triton-X, and $0.1 \%$ Triton-X. At the high dose of Triton-X, virtually all cells were injured and all incorporated radioactivity released. However, separation of radiolabeled eicosanoids by RP-HPLC revealed that under these conditions of increasing toxicity, progressively smaller proportions of incorporated radioactivity were released into media as eicosanoids. $0.1 \%$ Triton-X, which injured 10 -fold as many cells and released 10-fold as much total radioactivity as did A23187, released only one-tenth the quantity of eicosanoids as did A23187, and 


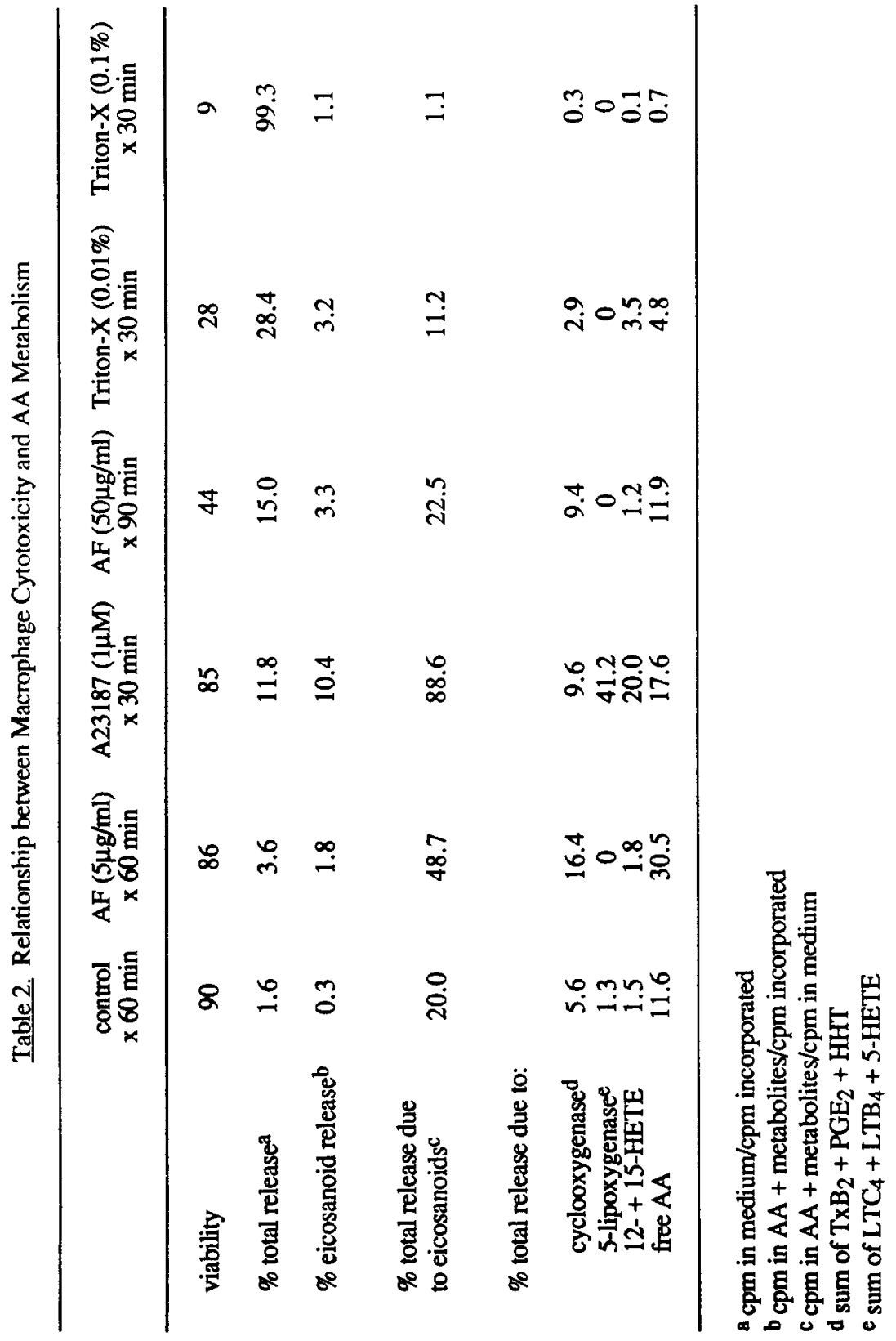


even less than the weaker agonist $\mathrm{AF}(5 \mu \mathrm{g} / \mathrm{ml})$. When radioactive eicosanoids were expressed relative to the total counts released into medium, it was apparent that with increasing toxicity, only a small proportion of these total counts were accounted for by free AA or its metabolites; presumably, the majority of these counts represent intact ${ }^{14} \mathrm{C}$ AA-containing phospholipids. Therefore, these data fail to support a simple relationship between membrane injury per se and the activities of phospholipase or either of the oxygenation enzymes.

\section{DISCUSSION}

The major finding of this study was that the oral gold compound AF triggered dose- and time-dependent release of arachidonate and its cyclooxygenase metabolites from cultures of rat AMs. This was demonstrated by a variety of techniques: 1) quantitation of total radioactivity (AA plus metabolites) released from ${ }^{14} \mathrm{C}$-AA prelabeled cells; 2) separation and quantitation of free ${ }^{14} \mathrm{C}$-AA released from prelabeled cells; and 3) quantitation by RIA of $\mathrm{TxB}_{2}$ and $\mathrm{PGE}_{2}$, the major cyclooxygenase metabolites synthesized by these cells (11). Furthermore, RP-HPLC analysis of eicosanoids synthesized by prelabeled cells confirmed that AF stimulated the release of AA and its metabolism via the cyclooxygenase pathway to $\mathrm{HHT} \sim \mathrm{TxB}_{2}>\mathrm{PGE}_{2}$. Of note, both RIAs and RP-HPLC analysis failed to demonstrate the synthesis of 5-lipoxygenase metabolites by AMs incubated with AF. Inhibition of prostaglandin synthesis by methylprednisolone pretreatment and by indomethacin supports the assumption that AFinduced AA metabolism proceeds via the actions of phospholipase and cyclonxygenase, as expected. While Snyder and associates (16) have demonstrated the capacity of AF to stimulate phospholipase $C$ activity in sonicates of a macrophage-like cell line, to our knowledge ours is the first report to document activation of AA metabolism by a gold compound in intact cells.

The rat AM has the capacity to synthesize large amounts of the 5-lipoxygenase products $\mathrm{LTB}_{4}, \mathrm{LTC}_{4}$, and 5-HETE along with cyclooxygenase products in response to classical agonists such as zymosan particles (10) or the calcium ionophore A23187 (14). However, AF failed to trigger 5-lipoxygenase metabolism despite the fact that it mobilized free AA and stimulated cyclooxygenase metabolism. This is reminiscent of our previous observations (14) with the sulfhydryl reactant $\mathrm{N}$-ethylmaleimide. Because in some experimental systems cyclooxygenase inhibition can shunt free AA to lipoxygenase products (17), we examined the effect of indomethacin on AF-induced eicosanoid synthesis. Despite the complete inhibition of $\mathrm{AF}$-induced $\mathrm{TxB}_{2}$ and $\mathrm{PGE}_{2}$ synthesis to levels below control values, indomethacin did not augment LT synthesis, indicating the lack of substrate shunting to the 5-lipoxygenase pathway under these conditions. It is conceivable that $\mathrm{AF}$ itself could complex with or catabolize 5-lipoxygenase eicosanoids, thereby interfering with our ability to detect them even if synthesized. However, other investigators $(18,19)$ have previously excluded such an effect of AF on exogenously added LT standards, and we have similarly shown that $\mathrm{N}$-ethylmaleimide did not influence recovery of exogenous LTs added to cultures of AMs (14). We therefore conclude that the lack of detectable 5-lipoxygenase eicosanoids in AF-treated cultures reflects a lack of synthesis. In a previous study we demonstrated that AF inhibited AM 5lipoxygenase metabolism stimulated by A23187 (8); this inhibition appears to be mediated, at least in part, by the depletion of intracellular ATP (unpublished results), a co-factor for the 5-lipoxygenase enzyme (20). We propose that the inability of AA mobilized by $A F$ to be metabolized via the 5-lipoxygenase pathway is due to the dual capacities of AF to both trigger AA release and inhibit the 5-lipoxygenase enzyme. 
The increase in the ratio of $\mathrm{TxB}_{2}: \mathrm{PGE}_{2}$ with increasing concentrations of $\mathrm{AF}$ may reflect the facts that synthesis of $\mathrm{PGE}_{2}(21)$, but not $\mathrm{TxB}_{2}(22)$, is dependent on reduced glutathione, and that AF dose-dependently depletes cellular glutathione (unpublished results). This is further suggested by the fact that levels of $\mathrm{LTC}_{4}$, whose synthesis is directly dependent on the conjugation of reduced glutathione to LTA4, but not levels of $\mathrm{LTB}_{4}$, declined progressively with increasing concentrations of AF. Since $\mathrm{TxA}_{2}$ has primarily pro-inflammatory actions (23) while $\mathrm{PGE}_{2}$ has prominent downregulatory effects on leukocyte activation (23), cellular immune function (24), and fibrogenesis (25), the increased $\mathrm{TxB}_{2}: \mathrm{PGE}_{2}$ ratio observed with $\mathrm{AF}$ treatment might result in a net augmentation of the inflammatory process.

Auranofin has previously been shown to be cytotoxic for a variety of cell types at concentrations ranging from $1-10 \mu \mathrm{g} / \mathrm{ml}$ (26). Our data demonstrated similar doseand time-dependent cytotoxicity for AMs, as judged by the inability to exclude the vital dye trypan blue. In order to ascertain the possible role of cytotoxicity in the ability of AF to trigger AA release and mertabolism, we conducted studies of arachidonate metabolism and viability using a broad range of agonists and toxins. If membrane injury alone were capable of activating the release and subsequent metabolism of AA, increases in eicosanoid synthesis would have been expected to parallel the increasing cytotoxicity caused by $50 \mu \mathrm{g} / \mathrm{ml} \mathrm{AF,} 0.01 \%$ Triton-X, and $0.1 \%$ Triton-X. However, the data in Table 2 demonstrate that this was not the case; indeed, an inverse relationship was observed between cytotoxicity and AA release and metabolism. The detergent Triton- $\mathrm{X}$ at $0.1 \%$, which released nearly all of the incorporated ${ }^{14} \mathrm{C}$ - $\mathrm{AA}$ into the medium, resulted in the synthesis of only $60 \%$ the quantity of eicosanoids as did the weak agonist $\mathrm{AF}$ and $10 \%$ as much as the potent agonist A23187. Since gold compounds cause lung injury in humans (5), any role that cytotoxicity might play in the capacity of AF to trigger AA release and metabolism may in fact be germane. Nonetheless, the results described above, as well as the fact that clear stimulation of AA release and/or metabolism was observed under AF incubation conditions unassociated with cytotoxicity (e.g., $5 \mu \mathrm{g} / \mathrm{ml} \mathrm{AF}$ for $60 \mathrm{~min}$ and $10 \mu \mathrm{g} / \mathrm{ml} \mathrm{AF}$ for $30 \mathrm{~min}$ ), leads us to conclude that the agonist activity of AF is independent of its cytotoxic potential. Rather, it is likely that the capacity of AF to trigger arachidonate metabolism is a consequence of its sulfhydryl or thiol reactivity (26), as this is a property shared by a variety of metallic $(27-29)$ and non-metallic $(14,30)$ sulfhydryl-reactive compounds.

Because macrophages are relatively enriched in their AA content as compared to neutrophils (31), and because they produce a diverse spectrum of cyclooxygenase and lipoxygenase eicosanoids (32), macrophage-derived eicosanoids have been proposed to play a prominent role in chronic inflammation. In the case of the AM, its significance is further emphasized by its strategic position as the resident effector cell of the lower respiratory tract (33). For these reasons, and because gold has been shown to accumulate in macrophages at inflammatory sites (34), including the lung (35), AA metabolism induced by $\mathrm{AF}$ at therapeutic concentrations may be relevant to the pathogenesis of pneumonitis which sometimes complicates the therapeutic use of gold (5), as well as the exacerbation of other inflammatory processes such as adjuvant arthritis (4). 


\section{ACKNOWLEDGMENTS}

The authors thank Dr. Bruce Wallin of Smith Kline \& French Laboratories for generous donation of auranofin, and Sharon Waltz for manuscript preparation. This work was supported by the Research Service of the Veterans Administration and by NIH HL01638 .

\section{REFERENCES}

1. Lipsky, P.E. Remission inducing therapy in rheumatoid arthritis. Am J Med 73 (suppl):40. 1983.

2. Muranaka, M., T. Miyamoto, T. Shida, J. Kabe, S. Makino, H. Okumura, K. Takeda, S. Suzuki, and Y. Horiuchi. Gold salt in the treatment of bronchial asthma - a double-blind study. Ann Allergy 40:132. 1978.

3. Bernstein, D.I., I. L. Bernstein, S. S. Bodenheimer, and R.G. Pietruska. An open study of auranofin in the treatment of steroid-dependent asthma. J Allergy Clin Immunol 81:6. 1988.

4. Haskard, D.O. and H.L.F. Currey. Gold exacerbates adjuvant arthritis in the rat. Ann Rheum Dis 43:350. 1984.

5. Winterbauer, R.H., K.R. Wilske, and R.F. Wheelis. Diffuse pulmonary injury associated with gold treatment. N Engl J Med 294:919. 1976.

6. Davies, P., R.J. Bonney, J.L. Humes, and F.A. Kuehl, Jr. The role of macrophage secretory products in chronic inflammatory processes. J Invest Derm 74:292. 1980.

7. Lipsky, P.E., K. Ugai, and M. Ziff. Alterations in human monocyte structure and function induced by incubation with sodium thiomalate. J Rheumatol $\underline{6}$ (suppl 5):130. 1979.

8. Peters-Golden, M. and C. Shelly. The oral gold compound auranofin triggers alveolar macrophage cyclooxygenase metabolism and inhibits leukotriene $\mathrm{C}_{4}$ synthesis. Am Rev Respir Dis 137 (Suppl): 91a. 1988.

9. Peters-Golden, M., J. Bathon, R. Flores, F. Hirata, and D.S. Newcombe. Glucocorticoid inhibition of zymosan-induced arachidonic acid release by rat alveolar macrophages. Am Rev Respir Dis 130:803. 1984.

10. Peters-Golden, $M$. and P. Thebert. Inhibition by methylprednisolone of $\mathbf{z y -}$ mosan-induced leukotriene synthesis in alveolar macrophages. Am Rev Respir Dis 135:1020. 1987.

11. Peters-Golden, $M$. and C. Shelly. Inhibitory effect of exogenous arachidonic acid on alveolar macrophage 5-lipoxygenase metabolism: role of ATP depletion. J Immunol 140:1958. 1988.

12. Sporn, P.H.S., M. Peters-Golden, and R.H. Simon. Hydrogen peroxideinduced arachidonic acid metabolism in the rat alveolar macrophage. Am Rev Respir Dis 137:49. 1988.

13. Westcott, J.Y., S. Chang, M. Balazy, D.O. Stene, P. Pradelles, J. Maclouf, N.F. Voelkel, and R.C. Murphy. Analysis of 6-keto PGF la 5-HETE, and $\mathrm{LTC}_{4}$ in rat lung: comparison of GC/MS, RIA, and EIA. Prostaglandins 31:857. 1986.

14. Peters-Golden, M. and C. Shelly. Modulation of alveolar macrophage-derived 5lipoxygenase products by the sulfhydryl reactant, N-ethylmaleimide. J. Biol Chem 262:10594. 1987.

15. Irvine, R.F. How is the level of free arachidonic acid controlled in mammalian cells? Biochem J 204:3. 1982. 
16. Snyder, R.M., C.K. Mirabelli, M.A. Clark, J.T. Ziegler, and S.T. Crooke. Effect of auranofin and other gold complexes on the activity of phospholipase C. Mol Pharmacol 32:437. 1987.

17. Engineer, D.M., U. Niederhauser, P.J. Piper, and P. Sirois. Release of mediators of anaphylaxis: inhibition of prostaglandin synthesis and the modification of the release of slow reacting substance of anaphylaxis and histamine. Br J Pharmacol 62:61. 1978.

18. Parente, J.E., K. Wong, P. Davis, J.F. Burka, and J.S. Percy. Effects of gold compounds on leukotriene $\mathrm{B}_{4}$, leukotriene $\mathrm{C}_{4}$, and prostaglandin $\mathrm{E}_{2}$ production by polymorphonuclear leukocytes. J Rheumatol 13:47. 1986.

19. Honda, Z., T. Iizasa, Y. Morita, K. Matsuta, Y. Nishida, and T. Miyamoto. Differential inhibitory effects of auranofin on leukotriene $\mathrm{B}_{4}$ and leukotriene $\mathrm{C}_{4}$ formation by human polymorphonuclear leukocytes. Biochem Pharmacol 36:1475. 1987.

20. Ochi, K., T. Yoshimoto, S. Yamamoto, K. Taniguchi, and T. Miyamoto. Arachidonate 5-lipoxygenase of guinea pig peritoneal polymorphonuclear leukocytes: activation by adenosine 5'-triphosphate. J Biol Chem 258:5754. 1983.

21. Ogino, N., T. Miyamoto, S. Yamamoto, and O. Hayaishi. Prostaglandin endoperoxide $\mathrm{E}$ isomerase from bovine vesicular gland microsomes, a glutathionerequiring enzyme. J Biol Chem 252:890. 1977.

22. Hammarstrom, S., and P. Falardeau. Resolution of prostaglandin endoperoxide synthase and thromboxane synthase of human platelets. Proc Natl Acad Sci USA 74:3691. 1977.

23. Higgs, G.A., R.M.J. Palmer, K.E. Eakins, and S. Moncada. The biochemistry of inflammation: arachidonic acid metabolism. Molec Aspects Med 4:276. 1981 .

24. Kunkel, S.L. The importance of arachidonate metabolism by immune and nonimmune cells (editorial). Lab Invest 58:119. 1988.

25. Saltzman, L., J. Moss, R. Berg, B. Hom, and R. Crystal. Modulation of collagen production by fibroblasts. Biochem J 204:25. 1982.

26. Snyder, R.M., C.K. Mirabelli, and S.T. Crooke. The cellular pharmacology of auranofin. Semin Arthritis Rheum 17:71, 1987.

27. Caprino, L., A.R. Togna, B. Cebo, N. Dolci, and G. Togna. In vitro effects of mercury on platelet aggregation, thromboxane and vascular prostacyclin production. Arch Toxicol Suppl $\underline{6}: 48.1983$.

28. Shier, W.T., and D.J. DuBourdieu. Stimulation of phospholipid hydrolysis and cell death by mercuric chloride: evidence of mercuric ion acting as a calciummimetic agent. Biochem Biophys Res Comm 110:758. 1983.

29. Elliott, G.R., M.J. van Batenburg, and I.L. Bonta. Copper modulation of macrophage cyclooxygenase metabolite synthesis. Prostaglandins 34:657. 1987.

30. Grundfest C.C., J. Chang, and D. Newcombe. Acrolein: a potent modulator of lung macrophage arachidonic acid metabolism. Biochim Biophys Acta 713:149. 1982 .

31. Mason, R.J., T.P. Stossel, and M. Vaughan. Lipids of alveolar macrophages, polymorphonuclear leukocytes, and their phagocytic vesicles. J Clin Invest 51:2399. 1972.

32. Chensuc, S.W. and S.L. Kunkcl. Arachidonic acid metabolism and macrophage activation. Clinics Lab Med 3:677. 1983.

33. Fels, A.O.S. and Z.A. Cohn. The alveolar macrophage. J Appl Physiol 60:353. 1986. 
34. Vernon-Roberts, B., J.L. Dore, J.D. Jessop, and W.J. Henderson. Selective concentration and localization of gold in macrophages of synovial and other tissues during and after chrysotherapy in rheumatoid patients. Ann Rheum Dis 35:477. 1976.

35. Garcia, J.G.N., A. Munim, K.M. Nugent, M. Bishop, P. Hoie-Garcia, N. Parhami, and B.A. Keogh. Alveolar macrophage gold retention in rheumatoid arthritis. J Rheumatol 14:435. 1987. 